\title{
STYLISED FACTS
}

\author{
Robert SKIDELSKY
}

I summarise Kaldor's "stylised facts" approach to economics through the lens of his 1966 inaugural lecture at Cambridge, "Causes of the Slow Rate of Economic Growth of the United Kingdom". I then defend this approach as a way of preventing economics from ossifying into pure formalism, fielding objections stemming from the Lucas critique, the advancement of econometrics, and the argument that stylised facts must depend on some prior theory. Finally, I argue that modern economics could benefit not only from his "stylised fact" approach, but also from his speculative boldness and substantive contributions to economic theory.

Keywords: Nicholas Kaldor, stylised facts, history of economic thought, economic methodology

JEL classification indices: B220, B310, B410, N140

I don't want to say too much about Nicky Kaldor's actual stylised facts, but about the methodological implication of the stylised facts approach. Paul Samuelson famously said, "those who can do economics, do it; those who can't, babble about methodology". Kaldor could certainly do economics, but he needed a methodology to enable him to do what he wanted to do. This is my excuse for babbling.

But let me start with his inaugural lecture at Cambridge in 1966, "Causes of the Slow Rate of Economic Growth of the United Kingdom". My connection with the Kaldors dated from about a year or so earlier when, as a research fellow of Nuffield College, Oxford, I taught Mary Kaldor politics as part of the Oxford PPE degree. Mary invited me to stay in Cambridge, and so I was in the audience for Kaldor's lecture.

Robert Skidelsky, Professor Emeritus at the Department of Economics, University of Warwick, U.K. E-mail: Robert.skidelsky@gmail.com 
Why did Kaldor inaugurate his Cambridge chair with the problem of slow growth? Because this was the problem of the day for economic policy in the UK. A Labour government had been elected two years previously, pledged to reverse the "13 wasted years" of Conservative rule. Over that period, the rate of growth of the UK economy had been persistently lower than that of its main European comparators: 2 per cent a year on average compared to 3-4 per cent for countries like Germany and France.

Kaldor was then chief economic adviser to the Labour government. As an economist he was, like Keynes, mainly interested in policy. If existing theory could not explain the salient facts, new theory had to be invented. The topic of slow growth was certainly topical.

According to Kaldor, the main engine of economic growth was growth in manufacturing output. This was because of increasing returns to scale in the manufacturing industry, and because output per person was higher in manufacturing than in agriculture and services. The faster the rate of growth of manufacturing output, the faster the rate of labour transfer from other sectors. In turn, reduced labour in these sectors will raise their productivity. Thus the faster the rate of growth of manufacturing output, the faster will be the rate of productivity growth for the economy as a whole (Verdoorn's Law).

As the scope for transferring labour from low or diminishing return activities dries up, the overall productivity growth induced by manufacturing growth will diminish, with the overall growth rate correspondingly reduced.

Britain's special problem of low growth arose from its "premature maturity". Early industrialisation had dried up the supply of labour from agriculture far sooner than in Germany or France. The only source of available low productivity labour was in services. (As far as I recall, he abstracted from immigration.) So labour needed to be transferred from the service to the manufacturing sector. This was the theoretical basis of the Selective Employment Tax, which Kaldor persuaded Chancellor James Callaghan to impose in 1966.

The "stylised fact" which underpinned Kaldor's modelling of Britain's slow growth rate was the historical relationship he discerned between the rate of transfer of labour from agriculture to manufacturing and the rate of economic growth. His thesis concerning Britain (and economic growth in general) provoked a huge debate in the literature, with a notable attempted refutation by Bob Rowthorn (1975). But it was typical of Kaldor that he was prepared to chance his arm, to stir up a fuss. I remember very well his perplexity when preparing to deliver the John Hicks memorial lecture at Oxford. Hicks was one of the most notable economists of the $20^{\text {th }}$ century. But theoretically, he was an arch-compromiser. "He never says anything positive," Kaldor complained, adding that "the great economists were all polemicists". 
Kaldor was an "imaginative activist". He was a strongly political economist. He would never have claimed that economics was value free.

As I came to develop a deeper understanding of economics, I became increasingly convinced that Kaldor's approach was the only way to prevent economics ossifying into pure formalism. "Stylised facts" was his methodological weapon, and I can do no better than quote from his essay "Capital Accumulation and Economic Growth" (1961), with its strongly implied attack on the neoclassical approach to model construction:

"We all agree that the basic requirement of any model is that it should be capable of explaining the characteristic features of the economic process as we find them in reality. It is no good starting off a model with the kind of abstraction which initially excludes the influence of forces which are mainly responsible for the behaviour of the economic variables under investigation; and on finding that the theory leads to results contrary to what we observe in reality, attributing this contrary movement to the compensating (or more than compensating) influence of residual factors that have been assumed away in the model.

Any theory must necessarily be based on abstractions; but the type of abstraction chosen cannot be decided in a vacuum... Hence the theorist, in choosing a particular theoretical approach, ought to start off with a summary of the facts which he regards as relevant to his problem. Since facts, as recorded by statisticians, are always subject to numerous snags and qualifications, and for that reason are incapable of being accurately summarised, the theorist, in my view, should be free to start with a 'stylized' view of the facts - i.e. concentrate on broad tendencies, ignoring individual detail, and proceed on the 'as if' method, i.e. construct a hypothesis that could account for these 'stylized' facts, without necessarily committing himself on the historical accuracy, or sufficiency, of the facts or tendencies thus summarized." (177-178).

In my opinion, the stylised facts approach stands up pretty well to the criticisms that have been made against it.

The first is that theory inevitably precedes the stylisation, and in practice determines it. The advocates of stylised facts claim to be making inductive hypotheses, but they actually start with some theory of how the system works, which enables them to identify the facts relevant to the problem. However, Kaldor surely has a good defence to this charge. Stylised facts are less the product of abstract theory than of historical reflection and what Keynes called "vigilant observation". Competing narratives suggest different theories; the ability to analyse historical arguments leads to a progressive improvement in theory. This defence both preserves the inductive basis of theory construction, and holds out the prospect of continuing theory improvement - a prospect surrendered by those who would leave theory testing to econometrics. Kaldor's stylised facts provided more phenomena 
to interrogate than statistical data would license on their own. This is brought out in Thomas Pikkety's massive historical survey of income inequality. He compellingly documents the persistence and latterly increase of inequality of wealth and incomes. Moreover, he believes this to be an inherent tendency under capitalism. But there is no analysis of the power relationships which might make this so. Indeed, there is nothing to link his neo-classical marginal productivity theory of allocation to his statistics, except some informal observations.

A better criticism of Kaldor's approach is that commitment to a particular set of stylised facts makes it very difficult to detect breaks in trend, which may of course be caused by the implementation of policies justified by these same stylized facts. This is the essence of the Lucas critique, and it has some force. However, it does not follow that theories based on stylised facts are less reliable than theories based on the so-called fundamentals of individual behaviour. This is simply an assertion that homo economicus is an appropriate abstraction of human behaviour at all times, a statement which is either vacuous or false.

A third criticism seems to me to have less force. Kaldor argued that the stylised fact approach was made necessary by the impossibility of establishing causal relationships by a purely statistical analysis. This has particular relevance to econometrics. It has recently been argued that this weakness can be overcome by randomised control trials. Borrowing from the medical trialling of new drugs, the randomised evaluation of public policy interventions has been used effectively in poor countries to develop effective vaccines for treating pneumonia and meningitis, to provide cash transfers for sending children to schools, and so on. But this approach has little to offer in the understanding of macroeconomic relationships, which still lies squarely in the domain of stylised facts. Stylised facts are virtually the only point at which the inductive process can make its entry point into macroeconomic model building.

Kaldor was in the tradition of classical economy. His stylised facts were directed to the classical issues of economic growth and income distribution. $\mathrm{He}$ interpreted Keynes (correctly in my view) as being a classical rather than a neoclassical economist, despite Keynes's neoclassical window-dressing. In other words, Kaldor was fundamentally opposed to the Robbins definition of economics as "the study of the relationship between unlimited wants and resources which have alternative uses". The full employment assumption implied by this definition is clear.

It is pretty extraordinary that this characterisation of the economic problem came from 1932, near the bottom of the Great Depression, when about 20 per cent of the available resources of capital and labour stood idle. Keynes, said Kaldor in 1983, asserted that "in normal circumstances, production in general was limited by effective demand which determined how much of the potential 
resources were potentially utilised". This was, of course, in sharp contrast to the Robbins assumption of full employment equilibrium. Capitalist economies were constrained by demand, not supply.

Though Kaldor was concerned with long-run growth and Keynes with the shortrun management of demand, there was no contradiction between the two, since post-war Keynesians like Kaldor assumed that Say's Law was now guaranteed by Keynesian full employment policy. This re-established the long-run growth agenda of the classical economists. So the Keynesian economists of that day produced growth models - Harrod-Domar, Solow, Rostow, etc. - geared chiefly to the problems of the developing world. This growth orientation did mean though that Kaldor was as much concerned with the conditions of supply as of demand, something evident in his 1966 inaugural lecture.

Kaldor was heir to the German economist Friedrich List, in that he regarded premature free trade as an obstacle to growth for those countries in the business of catching up with the leaders. Countries should seek to develop their dynamic potential rather than simply exploit their static comparative advantages. This required policies of protection and import substitution. Kaldor was passionately opposed to static equilibrium analysis.

From the 1960s onwards, he applied his dynamic analysis to Britain, which he saw as an example not just of premature maturity but premature senility, exemplified by the decline of the manufacturing sector. The 1983 House of Lords report calling for industrial policy to revive manufacturing bore the strong impress of Kaldor's arguments. It had no effect on the rampant Thatcherism then in power, but the arguments are now being taken seriously again, probably too late.

$$
* * *
$$

Kaldor lives on today, not just for his substantive contributions, but because his method opens up space for alternative issues and ways of doing economics. This is what many students today yearn for, depressed as they are by the aridity of much contemporary economics teaching, and eager to apply what they learn to real world problems - of stagnation, of poverty, of inequality, of climate change. In particular, the folloving questions have become increasingly clamant. What is growth for? What kinds of growth are good and bad? What will be the effect of automation on the future of human work? Though these issues did not much concern Kaldor at the time, we certainly need his speculative boldness and vigilant observation in order to conceptualise them. 